\title{
On Competition
}

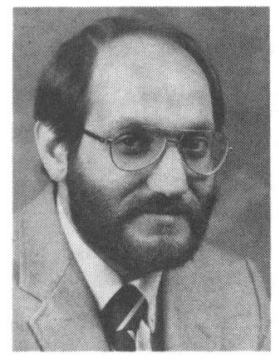

\section{Is the Materials Research Society an avaricious competitor running amuck among the learned societies?}

\author{
Elton N. Kaufmann \\ MRS President
}

Ts there an appropriate place for competition in the scientific research community? Yes, of course there is! The word however has multiple connotations. In some circumstances not entirely positive ones. In science, as in all walks of life and, in fact, in all processes known to man, competition is the natural order of things.

Alternative theories compete until comparison with experiment decides the winner. When a commodity is scarce, competition is often the process by which it is allocated. Researchers compete for jobs, for funding and, within many organizations, for position. Presumably when the process is just, it is healthy. The best people get the best jobs, and the robust funding goes to the best proposals. It is not my purpose to critique the system or to judge its success, although there is ample food for thought here and perhaps a reader of the Bulletin would care to contribute a letter to the editor.

My purpose here is to examine arenas in which competition is deemed inappropriate and relate that to professional societies in general and to MRS in particular. Take for example the acceptance process for technical articles submitted for archival journals. Set aside the obvious import of publication to the competitive position of the author in relation to his/her peers. Should the articles submitted compete with each other for a place in the journal? Here we strike a resonant chord with most who practice science. Nothing should limit the availability of knowledge. The media for its dissemination should not be scarce commodities. (Let's ignore the other side of this which is the difficulty in information retrieval when the data base is vast.) A submitted article ought to be tested against objective and consistent criteria of excellence by impartial judges and accepted or rejected without regard to available space or to the relative merits of other submitted articles. That this is the generally held view may be argued, but the expansion in journal pages to handle the volume of published research is clear.

There are other arenas where the argument is not quite as clean but where the "sanctity of knowledge" and the right of access to it leads us to feel that competition is not wholesome. Attendance at public forums, seminars, or courses could be included. Library usage is another good example. Let me digress from the scientific to the medical establishment long enough to make the following point. Few believe that patients in need of treatment should have to compete for medical services. The "sanctity of life" is an even more clear-cut guideline than that of knowledge. But look now at the role of the provider of the service. Be it a physician, a journal publisher, or a society which offers forums for the exchange of knowledge. They all do indeed find themselves in competition with each other from time to time when the demand for service is one which fluctuates or comes and goes with trends in the respective disciplines. Economic cycles have demonstrated the effect that a significant drop or qualitative change in demand has on the suppliers.

The onus of impropriety which attends competition among the seekers of the service has for some reason rubbed off on the providers. Only recently have physicians begun to advertise their services, a competitive stance still deemed unethical in conservative circles. It is, I believe, still viewed as a bit unseemly for an erudite archival journal to blatantly solicit contributions. And so it is that a society that is perceived to be competing for participation in some of its activities may be subject to a certain degree of ridicule. It has violated a vague definition of standards of ethical conduct and collegial behavior. Yes, the MRS has heard these murmurings in relation to nearly all of its activities. To wit: we have run symposia topics closely related to an existing forum; we have instituted an equipment show at our meetings; we have begun to offer short courses to our participants; we have initiated a second meeting in the Spring; and we are in the process now of evaluating Society sponsorship of an archival journal for materials research.

Is the Materials Research Society an avaricious competitor running amuck among learned societies? Indeed we are not! We have entered each new activity judiciously, gauging the real need and trying to avoid unnecessary overlap or duplication with existing resources. We believe the record so far speaks for itself. Where we have provided the same or similar services, the audience has been different. When we share the audience, the service has been unique. Tha caveat that I ask all who watch us to remember is that we will inevitably cross the topical and service areas to some extent of a great many other groups because of the interdisciplinary nature of our mission and our constituency. The rapid expansion of our Society on several fronts is in response to the demand for the unique approach we have developed. We have been approached several times in recent months with proposals for cooperation and cosponsorship of activities together with sister societies, and we welcome such overtures. In the present healthy climate for materials research, we are confident that a wide variety and combination of MRS and cooperative ventures will prove successful for all concerned and better serve the research community.

The form of competition which the MRS strongly favors is the competition of ideas which epitomizes the vitality of scientific research and which we try to foster in everything we do. MRS

Readers are invited to contribute their views on material matters in this column. 